\title{
Health symptoms related to pesticide exposure and agricultural tasks among rice farmers from northern Thailand
}

\author{
Ratana Sapbamrer · Sakorn Nata
}

Received: 9 May 2013/ Accepted: 18 June 2013/Published online: 9 July 2013

(C) The Japanese Society for Hygiene 2013

\begin{abstract}
Purpose The objective of this cross-sectional study was to investigate health symptoms related to occupational pesticide exposure and agricultural tasks in rice farmers.

Methods Data on demographic variables and health symptoms associated with pesticide exposure were collected from 182 rice farmers (exposed subjects) and 122 non-farmers (controlled group) using interviews and measuring whole blood acetylcholinesterase (AChE) activity during August and October 2012.

Results Rice farmers had a significantly lower median AChE activity than the controls (9,594 vs. 10,530 U/L, respectively) and a significantly higher prevalence of difficulty in breathing and chest pain [odds ratio (OR) 2.8, $P<0.01$ and OR 2.5, $P<0.05$, respectively]. The prevalence of dry throat and cramp was associated with those farmers who sprayed and mixed pesticides (OR 2.5 and 2.6 for dry throat, OR 2.5 and 2.9 for cramp, respectively; $P<0.01)$. The prevalence of numbness and diarrhea was associated with those farmers who scattered seed (OR 2.2, $P<0.01$ and OR 3.6, $P<0.05$, respectively). The prevalence of numbness and increasing anxiety was also associated with those farmers who harvested crops (OR 3.6, $P<0.01$ and OR 3.0, $P<0.05$, respectively).

Conclusions Our findings suggest that occupational pesticide exposure and agricultural tasks in the paddy field may be associated with the increasing prevalence of
\end{abstract}

R. Sapbamrer $(\square)$

School of Medicine, University of Phayao, 19 Moo2,

Mae Ka Subdistrict, Muang District, Phayao 56000, Thailand

e-mail: lekratana56@yahoo.com

S. Nata

Ban Tom Health Promoting Hospital, Muang District,

Phayao 56000, Thailand respiratory tract and muscle symptoms. This possibility warrants further investigation in more detail.

Keywords Pesticides - Symptoms · Farmers ·

Acetylcholinesterase $\cdot$ Paddy field

\section{Introduction}

Rice production is important for the Thai economy and for the labor force. During the last decade, the growing Thai population and a booming economy had led to intensification of rice production. The total production of rice in Thailand has increased from 29.5 million tons in 2003 to 37.9 million tons in 2012, and at the present time 25.7 million acres of paddy fields are under cultivation [1]. As a result, increasingly more pesticide is being used to increase this already massive production of rice. The most common types of pesticides imported into Thailand are herbicides, followed by insecticides and fungicides, respectively. Among the insecticides, organophosphates (OPs) and carbamates are most popular for protecting crops from insects. The use of pesticides in agriculture has been associated with occupational farm workers' health. The Disease Control Department of northern Thailand reported that 13.54 per 100,000 people in northern Thailand are hospitalized due to pesticide poisoning from farming. Most poisoning cases are related to the use of OPs, followed by herbicides and carbamates [2]. However, less severe cases of occupational poisoning do not require hospitalization and were, therefore, not included in the total cases reported.

Exposure to OPs and carbamates may cause both acute and chronic adverse health effects. The acute effects are related to the inhibition of cholinesterase during neurotransmission, and the cholinergic symptoms that present 
following exposure to these chemicals include dizziness, blurred vision, nausea, vomiting, cramp, and muscular weakness [3-6]. However, to date evidence supporting the chronic effects of low-level exposure are inconsistent and their mechanism not well understood [7]. Studies in animals have found that low levels of pesticide exposure can produce a variety of cholinergic symptoms ranging from enhanced maze learning to slowed nerve conduction [4]. Some studies in humans have revealed neurological and respiratory tract problems, including numbness, chest pain, weakness of arms and legs, and fatigue [8-10].

Several publications exist on acetylcholineasterase (AChE) activity and health symptoms among farm workers. However, the association between symptoms and agricultural tasks on a farm are not well established [11]. Agricultural tasks performed in paddy fields include spraying and mixing pesticides, scattering seed, and harvesting crops. The risks and consequences of being directly exposed to pesticides may differ according to the task and doses used in that task, resulting in different symptoms. Therefore, the aim of this study was to investigate the prevalence of health symptoms related to occupational pesticide exposure and their relation to agricultural tasks among rice farmers.

\section{Materials and methods}

Human ethic approval

This study was approved by the Human Experimentation Committee, University of Phayao, Thailand (Certificate of Ethical Clearance No. 55-02-04-0001), 21 November 2011.

\section{Study population}

Inclusion criteria were rice farmers and non-farmers, aged between 18 and 75 years old, who had lived for at least 5 years in Ban Tom Subdistrict, which is located close to Kwan Phayao Lake, northern Thailand. Those who met the inclusion criteria $(n=2,227)$ included 742 farmers (354 males, 388 females) and 1,485 non-farmers (640 males, 845 females). Of these 2,227 individuals, 182 farmers [90 (25.4\%) males, $92(23.7 \%)$ females] and 122 non-farmers [38 (5.9\%) males, 84 (9.9\%) females] agreed to volunteer as study subjects and signed a written consent form. The non-farmer group comprised individuals who had never done farm work and had never been exposed to pesticides in an occupational context. Data were collected through interview form and the measurement of AChE activity during August and October 2012, which is the period that pesticides are used for pest control in the paddy field.
Interviews

All subjects were asked questions on demographic data (age, education status, smoking, alcohol drinking), pesticide use, and health symptoms with regards to exposure to OPs and carbamates. The questions regarding health symptoms were asked within 1 month of enrollment. The questions were presented as 19 items in five sections focusing on: (1) respiratory tract symptoms (difficulty in breathing, chest pain, dry throat, cough); (2) muscle symptoms (numbness, cramp, muscle weakness); (3) neurobehavioral symptoms (headache, dizziness, epilepsy, balance problem, fatigue), (4) epithelial/mucosal surface symptoms (irritated eye, ulcer/blister, rash, red/white pimp); (5) other symptoms (diarrhea, friable nails, increasing anxiety). Supplemental questions for only farmers regarding practices and attitudes of pesticide use included years of farm work, area in rice cultivation, agricultural tasks on farm, types and frequency of pesticide use, reasons for pesticide use, source of pesticide information, and protective behavior to pesticide exposure. Regarding the agricultural task question, farmers were asked which tasks they performed in the paddy field: spraying pesticides, mixing pesticides, scattering seed, and harvesting crops.

\section{Measurement of AChE activity}

A 1-mL sample of blood was collected into an EDTA tube for measuring whole blood AChE activity. A modified procedure of the Ellman method [12] was used. Briefly, $20 \mu \mathrm{L}$ of whole blood was first diluted with $380 \mu \mathrm{L}$ of distilled water, and then $20 \mu \mathrm{L}$ of the diluted blood was mixed with $3 \mathrm{~mL}$ of $0.25 \mathrm{mM}$ dithiobisnitrobenzoic acid in phosphate buffer ( $\mathrm{pH} 7.7$ ). A $50-\mu \mathrm{L}$ aliquot of $5 \%$ acetylthiocholine iodide was added to the later solution, and the absorbance rate was then measured at $405 \mathrm{~nm}$ and $30^{\circ} \mathrm{C}$ at $30,60,60,90$, and $120 \mathrm{~s}$. The AChE activity $(\mathrm{U} / \mathrm{L})=$ change in absorbance in $1 \mathrm{~min} \times 11,700$. The activity reading was then multiplied by 20 . The normal limit for AChE activity in our laboratory ranged from 6,400 to $8,200 \mathrm{U} / \mathrm{L}$.

\section{Statistical analysis}

Data on demographic characteristics, practices, attitudes, and protective behavior to pesticide exposure were analyzed by using frequency, mean, median, standard deviation, range, and percentile ( $\mathrm{P} 25$ th $-\mathrm{P} 75$ th). The odds ratio (OR) and $95 \%$ confidence interval were calculated to assess symptoms related to occupational pesticide exposure and agricultural tasks in the paddy field. Due to the nonnormal distribution of variables, the Mann-Whitney $U$ test 
was used to compare AChE activity between farmers and controls at the significance level of 0.05 .

\section{Results}

Demographic data, AChE activity, practices, and attitudes

Demographic data and AChE activity among rice farmers and controls are presented in Table 1. The median age of the farmers and the controls was 55 years. Alcohol consumption and smoking were similar among the farmers and the controls. The educational status of the farmers was lower than that of the controls. The median AChE activity of the farmers $(9,594 \mathrm{U} / \mathrm{L})$ was significantly lower than that of the controls $(10,530 \mathrm{U} / \mathrm{L})$. The practices and attitudes regarding pesticide use by the 182 rice farmers are presented in Table 2. For each farmer, the mean area under cultivation was $3.0 \pm 2.2$ (range 0.1-11.9) acres, and the mean number of years working on a farm was $34.7 \pm 12.9$

Table 1 Demographic data and acetylcholinesterase activity of rice farmers and controls

\begin{tabular}{|c|c|c|c|}
\hline Parameters & $\begin{array}{l}\text { Farmers } \\
(n=182)\end{array}$ & $\begin{array}{l}\text { Controls } \\
(n=122)\end{array}$ & $P$ value \\
\hline \multicolumn{4}{|l|}{ Gender, $n(\%)^{\mathrm{a}}$} \\
\hline Male & $90(49.5)$ & $38(31.1)$ & $0.001 * *$ \\
\hline Female & $92(50.5)$ & 84 (68.9) & \\
\hline \multicolumn{4}{|l|}{ Education, $n(\%)^{\mathrm{a}}$} \\
\hline No education & 27 (14.8) & $11(9)$ & $0.014 *$ \\
\hline Primary level & $118(64.8)$ & $72(59)$ & \\
\hline Secondary level & $36(19.8)$ & $32(26.2)$ & \\
\hline Bachelor level & $1(0.5)$ & $7(5.7)$ & \\
\hline Alcohol drinking, $n(\%)^{\mathrm{a}}$ & & & 0.908 \\
\hline Yes & $63(34.6)$ & $44(36.1)$ & \\
\hline No & $119(65.4)$ & $78(63.9)$ & \\
\hline Smoking ${ }^{a}$ & & & 0.230 \\
\hline Yes & $36(19.8)$ & $15(12.3)$ & \\
\hline No & $146(80.2)$ & 107 (87.7) & \\
\hline Age (years) ${ }^{b}$ & & & 0.954 \\
\hline Mean \pm SD & $54.3 \pm 9.5$ & $53.4 \pm 14.4$ & \\
\hline Median (P25th-P75th) & $55(48-61)$ & $55(45-64)$ & \\
\hline AChE activity $(\mathrm{U} / \mathrm{L})^{\mathrm{b}}$ & & & $0.005^{* *}$ \\
\hline Mean $\pm \mathrm{SD}$ & $10295 \pm 3001$ & $11172 \pm 3090$ & \\
\hline Median (P25th-P75th) & $\begin{array}{l}9594 \\
\quad(8190-11934)\end{array}$ & $\begin{array}{l}10530 \\
(8892-12870)\end{array}$ & \\
\hline
\end{tabular}

SD, Standard deviation; P25th-P75th, percentile range

$* P<0.05 ; * * P<0.01$

${ }^{a}$ Obtained from chi-square analysis

${ }^{\text {b }}$ Obtained from Mann-Whitney $U$ test (range 5-60) years. The most common kinds of pesticide used in their rice field were insecticides $(n=154,84.6 \%)$, followed by herbicides ( $n=115,63.2 \%$ ), fungicides $(n=13,7.1 \%)$, and acaricides $(n=12,6.6 \%)$, respectively. Of the insecticides, OPs and carbamates with various trade names were the most commonly used types (data not shown). No significant association of AChE activity with gender, education level, years of farm work, and area under rice cultivation was found.

Table 2 Practices and attitudes regarding pesticide use by the rice farmers $(n=182)$

\begin{tabular}{|c|c|}
\hline Parameters & $n(\%)$ \\
\hline \multicolumn{2}{|l|}{ Pesticide use } \\
\hline Insecticides & $154(84.6)$ \\
\hline Herbicides & $115(63.2)$ \\
\hline Fungicides & $13(7.1)$ \\
\hline Acaricides & $12(6.6)$ \\
\hline \multicolumn{2}{|l|}{ Agricultural tasks } \\
\hline Spraying pesticides & $63(34.6)$ \\
\hline Mixing pesticides & $48(26.4)$ \\
\hline Scattering seed & $96(52.7)$ \\
\hline Harvesting & $155(85.2)$ \\
\hline \multicolumn{2}{|l|}{ Frequency of pesticide use } \\
\hline 1 time/month or less & $141(77.5)$ \\
\hline 1 time/week & $39(21.4)$ \\
\hline 2-3 times/week & $2(1.1)$ \\
\hline \multicolumn{2}{|l|}{ Source of pesticide information } \\
\hline Neighbors & $139(76.4)$ \\
\hline Television & $107(58.8)$ \\
\hline Merchants & $62(34.1)$ \\
\hline Radio & $56(30.8)$ \\
\hline Poster & $43(23.6)$ \\
\hline Brochure & $25(13.7)$ \\
\hline \multicolumn{2}{|l|}{ Reasons for pesticide use } \\
\hline Facing problem of pests & $112(61.5)$ \\
\hline Protecting against problem in advance & $101(55.5)$ \\
\hline Need for good product appearance & $79(43.4)$ \\
\hline Saving time, labor, and cost & $56(30.8)$ \\
\hline Following neighbor's practice & $40(22)$ \\
\hline \multicolumn{2}{|l|}{ Fate of empty containers } \\
\hline Burying in ground & $96(52.7)$ \\
\hline Throwing on garbage site & $53(29.1)$ \\
\hline Selling & $25(13.7)$ \\
\hline Burning & $20(11)$ \\
\hline Re-using & $4(2.2)$ \\
\hline Years in farm work (mean \pm SD) & $34.7 \pm 12.9$ \\
\hline Area (acres) under rice cultivation (mean $\pm \mathrm{SD}$ ) & $3.0 \pm 2.2$ \\
\hline
\end{tabular}


Most farmers $(n=141,77.5 \%)$ sprayed pesticides in their paddy field one time per month or less, whereas 39 farmers $(21.4 \%)$ used pesticides one time per week. In terms of agricultural tasks on farm, 63 (34.6\%) farmers sprayed pesticides themselves, 48 (26.4\%) mixed the pesticides, $96(52.7 \%)$ scattered seed, and $155(85.2 \%)$ harvested crops. Regarding the source of pesticide information, 139 (76.4\%) farmers received the information on pesticides from their neighbors versus 107 (58.8\%) who learned of pesticides from television. The most common disposal method for empty pesticide containers were burial in ground $(96,52.7 \%)$ or disposal on garbage site (53, $29.1 \%$ ). The major reasons to use pesticides were that farmers faced the problem of pests $(n=112,61.5 \%)$ and wanted to protect their plants against pests in advance $(n=101,55.5 \%)$.

Among the 63 farmers who sprayed pesticides, 53-63 (84.1-100\%) practiced good protective behavior before, during, and after application (Table 3). Of these 63 sprayers, $61(96.8 \%)$ checked spraying equipment and mixed pesticides outdoor, while $58(84.1 \%)$ mixed pesticides before application following the instructions given on the label. Almost all sprayers $(n=61,96.8 \%)$ wore boots and long-sleeved shirts during application, whereas only 47 (74.6\%) used goggles. After application, all farmers ( $n=63,100 \%$ ) washed equipment before storing it away, and the majority ( $n=59-61,93.7-96.8 \%$ ) took a bath, laundered, and changed clothes immediately. The median AChE activity at each protective measurement (except laundering clothes immediately) was not significantly different between sprayers who had good and bad protective behaviors.

Health symptoms related to occupational pesticide exposure

The prevalence of 19 symptoms related to pesticide exposure in rice farmers and controls is presented in Table 4. The OR and $95 \%$ CI were analyzed for matched pairs. Subjects recalled symptoms that presented within 1 month prior to the interview. In total 78 $(42.9 \%)$ farmers and $47(38.5 \%)$ controls presented these symptoms. The prevalence of difficulty in breathing and chest pain was significantly higher in farmers than in the controls (OR 2.8, $P<0.01$ and OR $2.5, P<0.05$, respectively).

Health symptoms associated with agricultural tasks in the paddy field

The prevalence of these 19 symptoms associated with agricultural tasks in the paddy field among 182 rice farmers
Table 3 Sprayers' protective behavior and acetylcholinesterase activity ( $n=63$ sprayers)

\begin{tabular}{|c|c|c|c|}
\hline $\begin{array}{l}\text { Protective } \\
\text { measure }\end{array}$ & $n(\%)$ & $\begin{array}{l}\text { Median of AChE } \\
\text { activity (U/L) }\end{array}$ & $P$ value $^{\mathrm{a}}$ \\
\hline \multicolumn{4}{|c|}{ Before application } \\
\hline \multicolumn{4}{|c|}{ Check spraying equipment } \\
\hline Yes & $61(96.8)$ & 9,360 & \multirow[t]{2}{*}{0.421} \\
\hline No & $2(3.2)$ & 10,881 & \\
\hline \multicolumn{4}{|c|}{ Mix pesticides outdoors } \\
\hline Yes & $61(96.8)$ & 9,594 & \multirow[t]{2}{*}{0.336} \\
\hline No & $2(3.2)$ & 8,541 & \\
\hline \multicolumn{4}{|c|}{ Choose pesticide that had the right label } \\
\hline Yes & $58(92.1)$ & 9,594 & \multirow[t]{2}{*}{0.359} \\
\hline No & $5(7.9)$ & 8,424 & \\
\hline \multicolumn{4}{|c|}{ Not using hands for mixing pesticide } \\
\hline Yes & $58(92.1)$ & 9,477 & \multirow[t]{2}{*}{0.770} \\
\hline No & $5(7.9)$ & 9,594 & \\
\hline \multicolumn{4}{|c|}{ Survey type of pests before buying pesticide } \\
\hline Yes & $56(88.9)$ & 9,477 & \multirow[t]{2}{*}{0.939} \\
\hline No & $7(11.1)$ & 10,062 & \\
\hline \multicolumn{4}{|c|}{ Read the directions on the pesticide label } \\
\hline Yes & $56(88.9)$ & 9,360 & \multirow[t]{2}{*}{0.352} \\
\hline No & 7 (11.1) & 10,764 & \\
\hline \multicolumn{4}{|c|}{ Mix pesticide as prescribed on label } \\
\hline Yes & $53(84.1)$ & 9,126 & \multirow[t]{2}{*}{0.309} \\
\hline No & $10(15.9)$ & 11,583 & \\
\hline \multicolumn{4}{|c|}{ During application } \\
\hline \multicolumn{4}{|c|}{ Wear boots } \\
\hline Yes & $61(96.8)$ & 13,104 & \multirow[t]{2}{*}{0.099} \\
\hline No & $2(3.2)$ & 9,360 & \\
\hline \multicolumn{4}{|c|}{ Wear long-sleeved shirt } \\
\hline Yes & $61(96.8)$ & 13,104 & \multirow[t]{2}{*}{0.099} \\
\hline No & $2(3.2)$ & 9,360 & \\
\hline \multicolumn{4}{|c|}{ Wear long pants } \\
\hline Yes & $60(95.2)$ & 11,700 & \multirow[t]{2}{*}{0.150} \\
\hline No & $3(4.8)$ & 9,243 & \\
\hline \multicolumn{4}{|l|}{ Wear hat } \\
\hline Yes & $60(95.2)$ & 9,477 & 0.375 \\
\hline No & $3(4.8)$ & 11,700 & \\
\hline Spray upv & & & \\
\hline Yes & $59(93.7)$ & 9,594 & 0.352 \\
\hline No & $4(6.3)$ & 8,541 & \\
\hline Wear glo & & & \\
\hline Yes & $58(92.1)$ & 9,243 & 0.450 \\
\hline No & $5(7.9)$ & 10,062 & \\
\hline Not eatin & drinking & & \\
\hline Yes & $57(90.5)$ & 9,360 & 0.935 \\
\hline No & $6(9.5)$ & 10,062 & \\
\hline Wear oral & mask & & \\
\hline Yes & $56(88.9)$ & 10,062 & 0.889 \\
\hline No & $7(11.1)$ & 9,477 & \\
\hline
\end{tabular}


Table 3 continued

\begin{tabular}{llll}
\hline $\begin{array}{l}\text { Protective } \\
\text { measure }\end{array}$ & $n(\%)$ & $\begin{array}{l}\text { Median of AChE } \\
\text { activity (U/L) }\end{array}$ & $P$ value $^{\mathrm{a}}$ \\
\hline Wear goggles & & & \\
Yes & $47(74.6)$ & 9,594 & 0.553 \\
No & $16(25.4)$ & 9,009 & \\
After application & & - \\
Wash equipment before keeping & & \\
Yes & $63(100)$ & 9,594 & 0.081 \\
No & $0(0)$ & & \\
Shower immediately & $61(96.8)$ & 9,594 & $0.025^{*}$ \\
Yes & $2(3.2)$ & 7,488 & \\
No & $61(96.8)$ & 9,594 & 0.877 \\
Launder clothes immediately & & \\
Yes & $2(3.2)$ & 6,903 & \\
No & $59(93.7)$ & 9,594 & \\
Change clothes immediately & & \\
Yes & $4(6.3)$ & 9,945 & \\
No & &
\end{tabular}

AChE, Acetylcholinesterase

$* P<0.05$

a Obtained from Mann-Whitney $U$ test

is presented in Table 5. The prevalence of dry throat and cramp was associated with those farmers who sprayed and mixed pesticides (OR 2.5 and 2.6 for dry throat, OR 2.5 and 2.9 for cramp; $P<0.01$, respectively). The prevalence of numbness and diarrhea was associated with those farmers who scattered seed (OR 2.2, $P<0.01$, and OR 3.6, $P<0.05$, respectively). The prevalence of numbness and increasing anxiety was also associated with the farmers who harvested crops (OR 3.6, $P<0.01$, and $\mathrm{OR} 3.0$, $P<0.05$, respectively).

\section{Discussion}

The measurement of AChE activity is known to be a biomarker of exposure to OPs and carbamates [13, 14]. AChE is an enzyme that destroys the neurotransmitter acetylcholine at neuromuscular junctions and cholinergic brain synapses. OPs and carbamates have a high affinity for binding and inhibiting AChE. When AChE is inhibited, acetylcholine builds up, resulting in over-stimulation of the cholinergic system and decreased AChE levels. The lower the AChE levels, the more likely it becomes that health symptoms due to pesticide poisoning will appear [13-16]. In our study we found that AChE activity was lower than in rice farmers that in controls due to occupational pesticide exposure of the former group. These results are in agreement with those from previous studies carried out among
Indian, American, Kenyan, Ghanaian, and Mexican farmworkers which found a significantly lower AChE activity among farmworkers exposed to pesticides compared with the control group [17-21]. However, in our study only six (3.3\%) farmers and none of the controls had an AChE level of $<6,400 \mathrm{U} / \mathrm{L}$, which is the lower limit of the normal range. It is therefore possible that most of our study subjects who were exposed to pesticides were exposed only to low levels and that this level of exposure was not high enough to inhibit AChE. Although the determination of AChE activity as a measure of exposure to OPs and carbamates is rapid, inexpensive, and convenient, this method lacks sensitivity and specificity at low levels of exposure $[22,23]$. As such, this method is useful for the diagnosis of acute poisoning, but it may be an unreliable indicator of low level exposure [24].

The major pesticide used in this study was insecticides $(84.6 \%)$, followed by herbicides, fungicides, and acaricides $(63.2,7.1,6.6 \%$, respectively). This finding corresponds with data on the import of pesticides into Thailand in 2011. The major imported pesticides were herbicides $(112,176.8 \mathrm{~kg})$, followed by insecticides $(34,672.2 \mathrm{~kg})$ and fungicides $(12,178.2 \mathrm{~kg})$, respectively. Although most of our farmers used pesticides to protect their crops, their AChE activity was within the normal range. One possible explanation is that most farmers used good protective behavior during farmwork, and they did not spray pesticides frequently. Among those farmers in our study who sprayed, most $(96.8 \%)$ used protective equipment and adopted safety practices during fieldwork. In addition, most of them $(77.5 \%)$ sprayed pesticides only one time per month or less. The health effects of exposure to pesticides depends on the frequency and the concentration of pesticide use, as well as on the implementation of personal protective measures [25-27]. Therefore, our results suggest that farmers who had proper protective behavior had decreased exposure to the highly poisonous pesticides.

OPs and carbamates affect cholinesterase activity in both the central and peripheral nervous systems. The sites of the peripheral nervous system which can be affected include the exocrine glands, eyes, gastrointestinal tract, respiratory tract, cardiovascular system, and skeletal muscles. Acute clinical symptoms of exposure to high doses of OPs and carbamates include salivation, lacrimation, urination, bradycardia, bronchorrhea, bronchospasm, respiratory insufficiency, tremors, muscle weakness, paralysis, restlessness, ataxia, confusion, and neurologic dysfunction [15]. Chronic and low level exposure to OPs and carbamates may result in the same symptom as acute exposure [28]. The severity of cholinesterase-inhibiting symptoms depend on the dose, route, and duration of pesticide exposure, the toxicity and lipid solubility of the pesticides, and AChE activity $[13,14]$. Several studies have reported 
Table 4 Prevalence of health symptoms $^{\mathrm{a}}$ related to occupational exposure between rice farmers and controls
OR, Odds ratio; $\mathrm{CI}$, confidence interval

$* P<0.05, * * P<0.01$

${ }^{a}$ Values are presented as the number with the percentage in parenthesis

\begin{tabular}{|c|c|c|c|c|}
\hline Symptoms & Farmers $(n=182)$ & Controls $(n=122)$ & OR & $95 \% \mathrm{Cl}$ \\
\hline \multicolumn{5}{|l|}{ Respiratory } \\
\hline Difficulty in breathing & $33(18.1)$ & $9(7.4)$ & $2.8^{* *}$ & $1.3,6.0$ \\
\hline Chest pain & $36(19.8)$ & $11(9)$ & $2.5^{*}$ & $1.2,5.1$ \\
\hline Dry throat & $43(23.6)$ & $30(24.6)$ & 0.9 & $0.6,1.6$ \\
\hline Cough & $51(28)$ & $29(23.8)$ & 1.2 & $0.7,2.1$ \\
\hline \multicolumn{5}{|l|}{ Muscle } \\
\hline Numbness & $75(41.2)$ & $47(38.5)$ & 1.1 & $0.7,1.8$ \\
\hline Cramp & $72(39.6)$ & $41(33.6)$ & 1.3 & $0.8,2.1$ \\
\hline Muscle weakness & $43(23.6)$ & $26(21.3)$ & 1.1 & $0.7,2.0$ \\
\hline \multicolumn{5}{|l|}{ Neurobehavioral } \\
\hline Headache & $56(30.8)$ & $28(23)$ & 1.5 & $0.9,2.5$ \\
\hline Dizziness & $63(34.6)$ & $34(27.9)$ & 1.4 & $0.8,2.3$ \\
\hline Epilepsy & $2(1.1)$ & $2(1.6)$ & 0.7 & $0.1,4.8$ \\
\hline Balance problem & $22(12.1)$ & $15(12.3)$ & 1.0 & $0.5,2.0$ \\
\hline Fatigue & $61(33.5)$ & $34(27.9)$ & 1.3 & $0.8,2.2$ \\
\hline \multicolumn{5}{|l|}{ Epithelial/mucosal surfaces } \\
\hline Irritated eye & $78(42.9)$ & $41(33.6)$ & 1.5 & $0.9,2.4$ \\
\hline Ulcer/blister & $4(2.2)$ & $3(2.5)$ & 0.9 & $0.2,4.1$ \\
\hline Rash & $29(15.9)$ & $20(16.4)$ & 1.0 & $0.5,1.8$ \\
\hline Red/whit pimp & $17(9.3)$ & $6(4.9)$ & 2.0 & $0.8,5.2$ \\
\hline \multicolumn{5}{|l|}{ Others } \\
\hline Friable nails & $6(3.3)$ & $3(2.5)$ & 1.4 & $0.3,5.5$ \\
\hline Diarrhea & $14(7.7)$ & $7(5.7)$ & 1.4 & $0.5,3.5$ \\
\hline Increasing anxiety & $78(42.9)$ & 45 (36.9) & 1.3 & $0.8,2.1$ \\
\hline
\end{tabular}

the chronic effects of pesticide exposure among farmers, including dermatitis, fatigue, respiratory tract problems, anxiety, and neurological deficits [8, 9]. A study involving 185 farmworkers in the Gaza Strip found that the most common symptoms related to pesticides exposure included eye/face irritation (64.3\%), dizziness (32.4\%), and difficulty in breathing/chest pain (28.1\%) [25]. A survey of Thai farmers reported that the health symptoms related to pesticide exposure included fatigue $(48.5 \%)$, dry throat (44.9\%), headache (40.4\%), dizziness (36.8\%), and numbness (29.4\%) [29]. A study among Philippine farmers with long-term exposure to pesticides also reported increasing occurrences of eye irritation (67\%), skin effects (45\%), and respiratory tract effects (45\%) compared with the controls [30]. In addition, some studies have reported a correlation between pesticide exposure, AChE level, and health symptoms, including respiratory tract, muscle, eye, and central nervous system symptoms [18, 31]. In contrast, our results indicate only effects related to difficulty in breathing (OR 2.8) and chest pain (OR 2.5), both of which are classified as a respiratory tract symptom. It is possible that the major route of pesticide exposure in our farmers was inhalation. Although the farmers protected themselves by using cloth mask when spraying pesticides, it is possible that the cloth mask was unable to protect pesticide exposure. However, exposure to OPs and carbamates by inhalation affect systemic circulation by passage through the liver, where it is metabolized [14, 32]. Thus, another explanation is that the respiratory effects found in our study are related to the variety of other pesticides also used in farming. Another possibility is that our farmers were exposed to low levels of pesticides and that these levels were not high enough to produce other symptoms. Indeed, several studies on low-level exposure to AChE have reported mild, inconsistent, and unexplained changes of the peripheral nerve system [7, 33, 34]. Acute poisoning is well defined in terms of threshold, but low-level effects shade into range of non-specific symptoms [7].

In terms of health symptoms related to the agricultural tasks described in our study, we found that the major symptoms among rice farmers spraying and mixing pesticides were dry throat and cramp. It is likely that pesticide exposure from spraying and mixing affected the respiratory tract and neuromuscular junction. The respiratory tract symptoms may be due to the use of inadequate protective equipment (cloth mask) during pesticide application. The major symptom among the farmers scattering seed and harvesting crops was numbness, suggesting that the exposure from scattering seed and harvesting crops affected the neuromuscular junction. These results are in agreement 


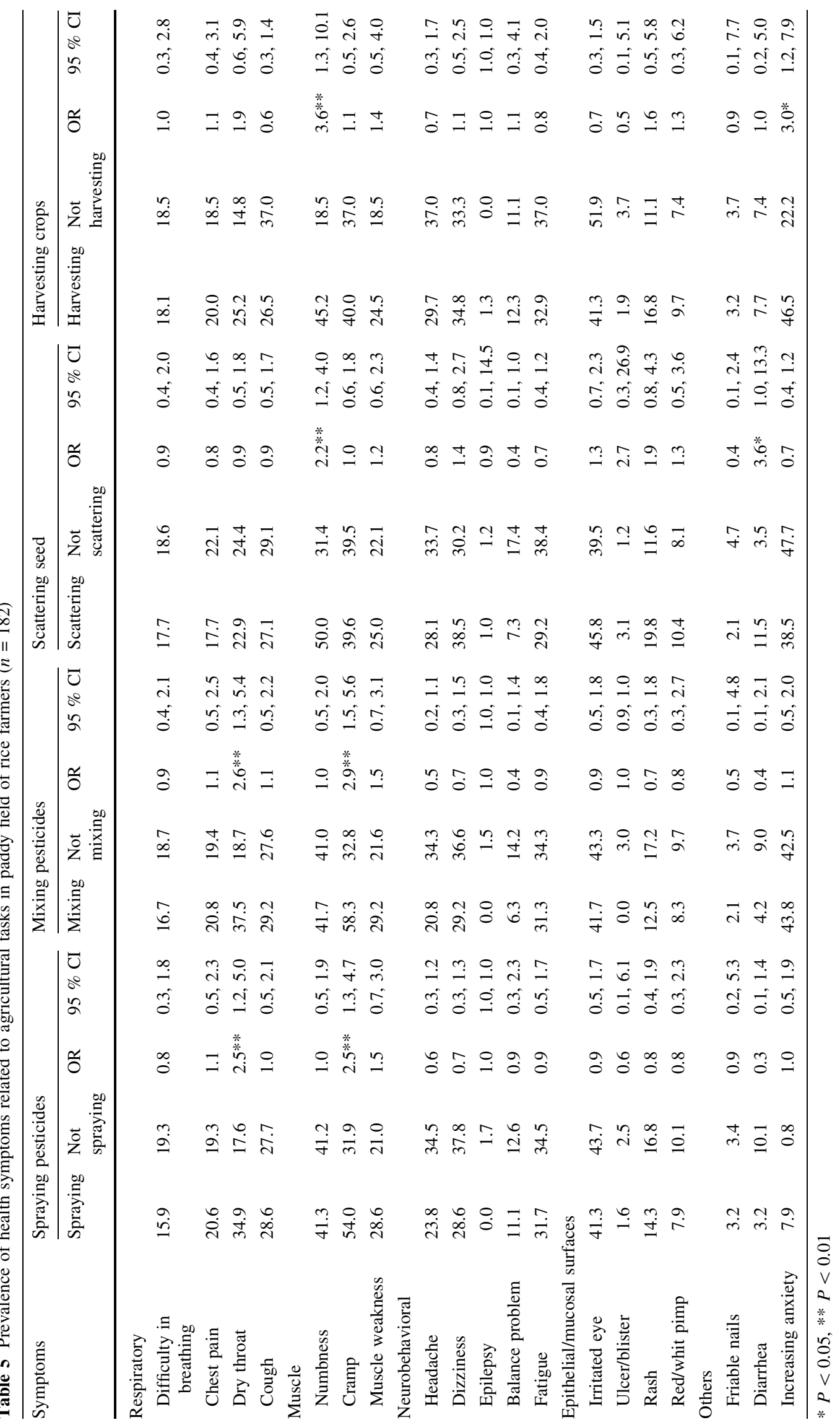


with those of Buranatrevedh and Sweatsriskul [35] who reported that the majority of abnormal physical health conditions among rice farmers were associated with the oral cavity, respiratory tract and musculoskeletal system. They also reported that musculoskeletal problems during seed the soaking/scattering and harvesting processes were caused by carrying heavy seed containers and lifting heavy rice sacks. Therefore, the numbness symptom that was reported by our farmers who scattered seed and harvested the crop may be due to an ergonomic problem. Almost all studies in this area report on health symptoms among sprayers and non-sprayers, and only a few have described symptoms related to other agricultural tasks. A study in 214 Indonesian farmers reported symptoms after the spraying of pesticides, with the most frequent symptoms being fatigue (60\%), muscle stiffness (54\%), dry throat (30\%), muscle weakness $(23 \%)$, dizziness $(21 \%)$, difficulty in breathing $(18.5 \%)$, and chest pain $(13.6 \%)$ [36]. Strong et al. [37] also found that the prevalence of shortness of breath was significantly higher in farmworkers spraying, mixing, and applying pesticides than in those who did not. Stokes et al. [38] also reported a higher prevalence of headache, muscle pain, sick stomach, and psychological problems during the growing season than during the offseason.

There are several limitations to this study. Firstly, farmers were exposed to other pesticides in addition to OPs and carbamates, such as fungicides and pyrethroids. Consequently, it is difficult to determine which types of pesticides caused the health symptoms described herein. Secondly, The AChE activity in almost all of our subjects was in the normal range, indicating that they had been exposed-if at all-to only low levels of OPs and carbamates. This low level of exposure may not high enough to produce definitive symptoms, thereby limiting the interpretation of our data. Thirdly, health symptoms have multiple causes and may not be attributed to pesticide exposure. Numbness may be due to ergonomic problems, and dry throat may be due to infectious agents as well as pesticides. Finally, the study design did not control a number of confounding factors, such as gender, education level, exposure to previous OPs, carbamate poisoning, and underlying diseases. Thus, these factors may also account for (some of) the symptoms reported.

Taken on a whole, our findings suggest that occupational pesticide exposure and agricultural tasks in paddy field may be associated with an increasing prevalence of respiratory tract and muscle symptoms. AChE activity is a biomarker of exposure to OPs and carbamates, and the activity in rice farmers was significantly lower than that in the controls. However, exposure to various pesticides and the low dose of exposure make it difficult to interpret our data. Thus, further studies are required to evaluate health symptoms among farmers with high exposure to OPs and carbamates.

Acknowledgments This study was funded by University of Phayao Grant 2012. We are grateful to the School of Science, School of Medical Science, School of Allied Health Science, and School of Medicine, University of Phayao for their assistance. We are also grateful to Dr. Banjong Chairinkham for editing the manuscript. We thank all volunteers and all officers in Baan Tom Health Promoting Hospital for their cooperation.

Conflict of interest None.

\section{References}

1. Thai Rice Exporters Association. Rice production. Thailand. Available at: http://www.thairiceexporters.r.th/production.htm. Accessed 1 April 2013.

2. Srisomboon N. Existing conditions of pesticides poisoning between January and December 2012 in northern Thailand [eLetter]. Available at: http://dpc10.ddc.moph.go.th. Accessed 20 Nov 2012.

3. Clarke EE, Levy LS, Spurgeon A, Calvert IA. The problems associated with pesticide use by irrigation workers in Ghana. Occup Med (Lond). 1997;47:301-8.

4. Ray DE, Richards PG. The potential for toxic effects of chronic, lowdose exposure to organophosphates. Toxicol Lett. 2001;120:343-51.

5. Colosio C, Tiramani M, Maroni M. Neurobehavioral effects of pesticides: state of the art. Neurotoxicology. 2003;24:577-91.

6. Stephens R, Sreenivasan B. Neuropsychological effects of longterm low-level organophosphate exposure in orchard sprayers in England. Arch Environ Health. 2004;59:566-74.

7. Ray DE. Chronic effects of low level exposure to anticholinesterases-a mechanistic review. Toxicol Lett. 1998;28:527-33.

8. Cordes DH, Rea DF. Health hazards of farming. Am Farm Phys. 1988;38:233-43.

9. Moses M. Pesticide-related health problems and farmworkers. AAOHN J. 1989;37:115-30.

10. Abou-donai MB. Organophosphorus ester-induced chronic neurotoxicity. Arch Environ Health. 2003;58:484-97.

11. Coronado GD, Thompson B, Strong L, Griffith WC, Islas I. Agricultural task and exposure to organophosphate pesticides among farmworkers. Environ Health Perspect. 2004;112:142-7.

12. Ellman GL, Courtney KD, Andres V, Featherstone RM. A new and rapid colorimetric determination of acetylcholinesterase activity. Biochem Pharmacol. 1961;7:88-95.

13. Gupta RC. Chapter 39 organophosphates and carbamates. In: Gupta RC, editor. Veterinary toxicology: basic and clinical principles, 1st edn. New York: Academic Press; 2007. p. 477-87.

14. Extension Toxicology Network. Cholinesterase inhibition. Available at: http://pmep.cce.cornell.edu/profiles/extoxnet. Accessed 6 July 2013.

15. Ecobichon DJ. Toxic effects of pesticides. In: Klaassen CD, editor. Casarett \& Doull's toxicology: the basic science of poisons. 5th ed. USA: McGraw-Hill; 1996. p. 643-89.

16. Bajgar J. Complex view on poisoning with nerve agents and organophosphates. Acta Med. 2005;48:3-21.

17. Ciesielski S, Loomis DP, Mims SR, Auer A. Pesticide exposure, cholinesterase depression, and symptoms among North Carolina migrant farmworkers. Am J Public Health. 1994;84:446-51.

18. Ohayo-Mitoko GJ, Kromhout H, Simwa JM, Boleij J, Heederik D. Self reported symptoms and inhibition of acetylcholinesterase activity among Kenyan agricultural workers. Occup Environ Med. 2000;57:195-200. 
19. Rendón von Osten J, Epomex C, Tinoco-Ojanguren R, Soares AM, Guilhermino L. Effect of pesticide exposure on acetylcholinesterase activity in subsistence farmers from Campeche, Mexico. Arch Environ Health. 2005;59:418-25.

20. Ntow WJ, Tagoe LM, Drechsel P, Kelderman P, Nyarko E, Gijzen HJ. Occupational exposure to pesticides: blood cholinesterase activity in a farming community in Ghana. Arch Environ Contam Toxicol. 2009;56:623-30.

21. Singh S, Kumar V, Thakur S, Banerjee BD, Chandna S, et al. DNA damage and cholinesterase activity in occupational workers exposed to pesticides. Environ Toxicol Pharmacol. 2011;31: $278-85$.

22. Worek F, Koller M, Thiermann H, Szinicz L. Diagnostic aspects of organophosphate poisoning. Toxicology. 2005;214:182-9.

23. Tsai JR, Sheu CC, Cheng MH, Hung JY, Wang CS, et al. Organophosphate poisoning: 10 years of experience in southern Taiwan. Kaohsiung J Med Sci. 2007;23:112-9.

24. Richter ED, Kaspi L, Gordon M, Levy S, Israeli R, Gruener N. Monitoring for neurotoxic effects from low level exposures to organophosphate pesticides. Sci Total Environ. 1984;32:335-44.

25. Yassin MM, Abu Mourad TA, Safi JM. Knowledge, attitude, practice, and toxicity symptoms associated with pesticide use among farm workers in the Gaza Strip. Occup Environ Med. 2002;59:387-93.

26. Recena MCP, Caldas ED, Pires DX, Pontes ERJC. Pesticides exposure in Culturama, Brazil-knowledge, attitudes, and practices. Environ Res. 2006;102:230-6.

27. Lein PJ, Bonner MR, Farahat FM, Olsen JR, Rohlman DS, Experimental strategy for translational studies of organophosphorus pesticide neurotoxicity based on real-world occupational exposures to chlorpyrifos. Neurotoxicology. 2012;33:660-8.

28. Davies R, Ahmed G, Freer T. Chronic exposure to organophosphates: background and clinical picture. Adv Psychiatr Treat. 2000;6:187-92.
29. Sapbamrer R, Damrongsat A, Kongtan P. Health impact assessment of pesticide use among farmers from Phayao Province, Northern Thailand. J Environ Res. 2011;33:1-11.

30. Pingali PL, Marquez CB, Palis FG. Pesticides and Philippine rice farmer health: a medical and economic analysis. Am J Agric Economics. 1994;76:587-92.

31. Smit LAM, Heederk D, van Wendel-de-Joode BN, Peiris-John RJ, van der Hoek W. Neurological symptoms among Sri Lankan farmers occupationally exposed to acetylcholinesterase-inhibiting insecticides. Am J Ind Med. 2003;44:254-64.

32. Peiris-John RJ, Ruberu DK, Wickremasinghe AR, Van-der-Hock W. Low-level exposure to organophosphate pesticides leads to restrictive lung dysfunction. Res Med. 2005;99:1319-24.

33. Lotti M. Low-level exposures to organophosphorus esters and peripheral nerve function. Muscle Nerve. 2002;25:492-504.

34. Lotti M, Moretto A. Organophosphate-induced delayed polyneuropathy. Toxicol Rev. 2005;24:37-49.

35. Buranatrevedh S, Sweatsriskul P. Model development for health promotion and control of agricultural occupational health hazards and accidents in Pathumthani, Thailand. Ind Health. 2005;43: 669-76.

36. Kishi M, Hirschhorn N, Djajadisastra M, Satterlee LN, Strowman S, Dilts R. Relationship of pesticide spraying to signs and symptoms in Indonesian farmers. Scand J Work Environ Health. 1995;21:124-33.

37. Strong LL, Thompson B, Coronado GD, Griffith WC, Vigoren EM, Islas I. Health symptoms and exposure to organophosphate pesticides in farmworkers. Am J Ind Med. 2004;46:599-606.

38. Stokes L, Stark A, Marshall E, Narang A. Neurotoxicity among pesticide applicators exposed to organophosphates. Occup Environ Med. 1995;52:648-53. 